\title{
A-Site Cation Engineering for Efficient Blue-Emissive Perovskite Light-Emitting Diodes
}

\author{
Jong Hyun Park ${ }^{1}$, Chung Hyeon Jang ${ }^{1} \mathbb{1}$, Eui Dae Jung ${ }^{1}$, Seungjin Lee ${ }^{2, *}$, \\ Myoung Hoon Song ${ }^{1, *}$ and Bo Ram Lee ${ }^{3, *}$ \\ 1 School of Materials Science and Engineering, Ulsan National Institute of Science and Technology (UNIST), \\ Ulsan 44919, Korea; kookkno1@unist.ac.kr (J.H.P.); karals@unist.ac.kr (C.H.J.); jed9318@unist.ac.kr (E.D.J.) \\ 2 Department of Electrical and Computer Engineering, University of Toronto, Toronto, ON M5S 3G4, Canada \\ 3 Department of Physics, Pukyong National University, Busan 48513, Korea \\ * Correspondence: seungjin.lee@utoronto.ca (S.L.); mhsong@unist.ac.kr (M.H.S.); brlee@pknu.ac.kr (B.R.L.); \\ Tel.: +82-52-217-2316 (M.H.S.); +82-51-629-5562 (B.R.L.)
}

Received: 25 November 2020; Accepted: 15 December 2020; Published: 18 December 2020

check for updates

\begin{abstract}
Metal halide perovskites have been investigated for the next-generation light-emitting materials because of their advantages such as high photoluminescence quantum yield (PLQY), excellent color purity, and facile color tunability. Recently, red- and green-emissive perovskite light-emitting diodes (PeLEDs) have shown an external quantum efficiency (EQE) of over $20 \%$, whereas there is still room for improvement for blue emissive PeLEDs. By controlling the halide compositions of chloride $\left(\mathrm{Cl}^{-}\right)$and bromide $\left(\mathrm{Br}^{-}\right)$, the bandgap of perovskites can be easily tuned for blue emission. However, halide segregation easily occurrs in the mixed-halide perovskite under light irradiation and LED operation because of poor phase stability. Here, we explore the effect of A-site cation engineering on the phase stability of the mixed-halide perovskites and find that a judicious selection of low dipole moment A cation (formamidinium or cesium) suppresses the halide segregation. This enables efficient bandgap tuning and electroluminescence stability for sky blue emissive PeLEDs over the current density of $15 \mathrm{~mA} / \mathrm{cm}^{2}$.
\end{abstract}

Keywords: perovskite light-emitting diodes; blue emission; device stability; A-site cation; halide segregation

\section{Introduction}

Metal halide perovskites (MHPs) are composed of three elements with $\mathrm{ABX}_{3}$ structures, where the A-site is typically occupied by an organic cation such as methylammonium $\left(\mathrm{MA}^{+}\right)$, formamidinium $\left(\mathrm{FA}^{+}\right)$or an inorganic cation cesium $\left(\mathrm{Cs}^{+}\right)$; the B-site is occupied by a lead $\left(\mathrm{Pb}^{2+}\right)$ or tin $\left(\mathrm{Sn}^{2+}\right)$ ion; and the $\mathrm{X}$-site is occupied by a halide anion such as chloride $\left(\mathrm{Cl}^{-}\right)$, bromide $\left(\mathrm{Br}^{-}\right)$, iodide $\left(\mathrm{I}^{-}\right)$or a mix of the three. In terms of light emitting devices, the most attractive property of perovskite is the easily tunable nature of the bandgap, and thus the emission wavelength, by adjusting the halide composition; wavelengths across the electromagnetic spectrum from deep-blue to infrared range have been reported. MHPs have excellent luminescence properties including high color purity (full width at half-maximum (FWHM) $\leq 20 \mathrm{~nm}$ ) and a high photoluminescence quantum yield (PLQY) of over 90\% [1-8]. In this aspect, intensive investigation of the perovskites-based light-emitting diodes (PeLEDs) has been conducted for the next-generation display and solid-state lighting since first room temperature PeLEDs were demonstrated [1]. Recently, red- and green-emissive PeLEDs achieved high external quantum efficiencies (EQEs) of over $20 \%$ and showed great potential for display applications $[7,9,10]$, whereas blue-emissive PeLEDs have shown much lower EQEs of 12\% [11-13]; this poor performance of blue-emissive PeLEDs is still considered to be one of the most challenging barriers to their device applications. 
In general, the emission wavelength could be tuned in multiple ways to make blue-emissive PeLEDs: size control of perovskite nanocrystals; various doping and ion substitution; and control of (mixed) halide composition. The first approach relies on the quantum confinement effect, which is evidenced when the nanocrystal size approaches the exciton Bohr radius, achieving blue emission [12]. The second approach relies on lattice strain and electronic band structure modification [14]. However, the challenges involved in the precise control of the nanocrystal size and difficulty of achieving deep-blue emission usually favor the second approach, where the required emission wavelength is obtained by controlling the composition of $\mathrm{Br}$ and $\mathrm{Cl}$ in a mixed-halide system. The band gap of mixed-halide perovskite is known to increase with the $\mathrm{Cl}$ content, thereby resulting in a more blue-shifted emission $[15,16]$. However, mixed-halide perovskites are known to suffer from photo- and current-induced halide segregation upon device operation $[17,18]$, which is detrimental to achieving a stable emission wavelength. Various reports suggest the different origin of light-induced halide segregation: Ginsberg et al. [19,20] and Gao et al. [21] suggest local strain upon polaron formation and localization, whereas Herz et al. [8] and McGehee et al. [22,23] point at surface and inner defects trapping the charge carriers, resulting in an internal electric field to induce halide segregation. As the magnitude of this strain also depends on the intrinsic properties of ions in the perovskite structure, a judicious choice of A-site organic/inorganic cations could mitigate the occurrence of halide segregation.

Many properties of metal halide perovskite such as band gap, crystal stability, and optical properties are also highly dependent on the nature of A-site cations. First, ionic radiuses are different such as: $\mathrm{FA}=2.79 \AA, \mathrm{MA}=2.70 \AA, \mathrm{Cs}=1.81 \AA$ [24]. Furthermore, unlike the spherical Cs, the organic molecules FA and MA have a dipole moment of 0.21 and 2.29 Debye, respectively [25]. Following this idea of A-site cation engineering, we report the device performances of sky blue-emissive quasi-2D perovskite PeLEDs of composition $\mathrm{PMA}_{2} \mathrm{~A}_{2} \mathrm{~Pb}_{3} \mathrm{Br}_{8} \mathrm{Cl}_{2}$ (PMA = Phenylmethylammonium) with varying A-site cations $\left(\mathrm{MA}^{+}, \mathrm{FA}^{+}\right.$and $\left.\mathrm{Cs}^{+}\right)$. We explore the effect of A-site cation engineering on the bandgap tunability and the phase stability of mixed-halide perovskites containing $\mathrm{Br}$ and $\mathrm{Cl}$. PeLEDs show luminances of 1560,280 and $790 \mathrm{~cd} / \mathrm{m}^{2}$, EQEs of $1.41,0.88$ and $0.42 \%$, and a wavelength of 509,494 , $488 \mathrm{~nm}$ for the A-site cations FA, MA and Cs, respectively. Moreover, PeLEDs using FA and Cs cations show highly improved electroluminescence (EL) spectrum stability compared to those using MA during device operation, which indicates substantially reduced halide segregation in FA and Cs-based PeLEDs. As a result, we demonstrate negligible EL spectrum changes under high current density of more than $15 \mathrm{~mA} / \mathrm{cm}^{2}$ with FA, Cs-based quasi-2D PeLEDs.

\section{Materials and Methods}

\subsection{Materials and Chemicals}

Poly(3,4-ethylenedioxythiophene):polystyrenesulfonate (PEDOT:PSS, AI 4083, Clevios, Heraeus, Leverkusen, Germany), formamidinium bromide (FABr, Tokyo Chemical Industry, Tokyo, Japan), methylammonium bromide (MABr, GreatCell Energy, Queanbeyan, Australia), cesium bromide (CsBr, SigmaAldrich, Seoul, Korea), phenylmethylammonium chloride (PMACl, Tokyo Chemical Industry, Tokyo, Japan), and 2,2',2'-(1,3,5-benzinetriyl)-tris(1-phenyl-1H-benzimidazole) (TPBi, OSM, Seoul, Korea) were used without any further purification. N,N-Dimethylformamide (DMF), dimethyl sulfoxide (DMSO), and chlorobenzene were purchased from SigmaAldrich (Seoul, Korea).

\subsection{Perovskite Precursor Preparation}

The precursor solution (qausi-2D $\mathrm{PMA}_{2} \mathrm{FA}_{2} \mathrm{~Pb}_{2} \mathrm{Br}_{8} \mathrm{Cl}_{2}$ ) was prepared by mixing $110.1 \mathrm{mg} \mathrm{PbBr}_{2}$, $28.9 \mathrm{mg} \mathrm{PMACl}$, and $25.1 \mathrm{mg} \mathrm{FABr}$ in a DMF/DMSO co-solvent ratio of 7:3 (v:v). The precursor solution (quasi-2D $\mathrm{PMA}_{2} \mathrm{MA}_{2} \mathrm{~Pb}_{2} \mathrm{Br}_{8} \mathrm{Cl}_{2}$ ) was prepared by mixing $110.1 \mathrm{mg} \mathrm{PbBr}_{2}, 28.9 \mathrm{mg} \mathrm{PMACl}$, and $22.5 \mathrm{mg} \mathrm{MABr}$ in a DMF/DMSO co-solvent ratio of 7:3 (v:v). The precursor solution (quasi-2D $\mathrm{PMA}_{2} \mathrm{Cs}_{2} \mathrm{~Pb}_{2} \mathrm{Br}_{8} \mathrm{Cl}_{2}$ ) was prepared by mixing $110.1 \mathrm{mg} \mathrm{PbBr} 2,28.9 \mathrm{mg} \mathrm{PMACl}$, and $42.8 \mathrm{mg} \mathrm{CsBr}$ in a DMSO solvent $(0.3 \mathrm{M})$ 


\subsection{Device Fabrication}

A patterned indium tin oxide (ITO)-coated glass substrate was ultraviolet-ozone treated for $30 \mathrm{~min}$. The PEDOT:PSS was prepared using spin-coating at $5000 \mathrm{rpm}$ for $45 \mathrm{~s}$. The samples were transferred into the glovebox and annealed at $135^{\circ} \mathrm{C}$ for $10 \mathrm{~min}$. A $0.45 \mu \mathrm{m}$ hydrophilic filter were used for the perovskite precursor solutions filtration. Filtered perovskite precursor solutions were spin-coated at $3000 \mathrm{rpm}$ for $50 \mathrm{~s}$. The antisolvent, chlorobenzene $(300 \mu \mathrm{L})$, was dropped after $30 \mathrm{~s}$, as described elsewhere [26]. TPBi, lithium fluoride ( $\mathrm{LiF})$, and aluminum $(\mathrm{Al})$ electrodes were evaporated using a thermal evaporator.

\subsection{Device Characterization}

The measurements of the current $(\mathrm{J})$, voltage $(\mathrm{V})$, luminance $(\mathrm{L})$ and device efficiencies of the devices were performed in air with encapsulation. J-V data were measured using a computer-controlled Keithley 2400 source meter (Tektronix, Beaverton, OR, USA), and a Konica Minolta spectroradiometer (CS-2000, Toyko, Japan) was used to measure the luminance of the device.

\subsection{Steady-State Photoluminescence (PL) Measurements}

Steady-State PL was recorded using a time-correlated single-photon counting (TCSPC) setup (FluoTime 300, Berlin, Germany). The samples were photoexcited using a $375 \mathrm{~nm}$ pulsed ( 70 ps) diode laser coupled to a PDL 820 laser drive. A PicoHarp TCSPC module (Berlin, Germany) with a photomultiplier tube (PMA-C 182-N-M, Berlin, Germany) was used to detect the photons emitted from the perovskite films.

\subsection{Scanning Electron Microscope (SEM) Measurements}

Perovskite films with FA, MA, and Cs-based quasi-2D composition were measured using a Nanonova 230 FEI SEM (accelerating voltage of $10 \mathrm{kV}$ ). A sputter coater (Emitech K575x, Tescan, Brno, Czech Republic) was used to deposit a $5 \mathrm{~nm}$ platinum layer to prevent charging effects.

\subsection{X-Ray Diffraction (XRD) Measurements}

The XRD patterns of FA, MA, and Cs-based quasi-2D perovskite films were obtained using a D/MAX2500V/PC (Rigaku, Toyko, Japan) with a Cu K $\alpha$ radiation $(\lambda=1.5405 \AA$ ).

\section{Results and Discussion}

The sky-blue emissive PeLEDs were constructed with the following structures: ITO as anodes; PEDOT:PSS as hole transporting layers; quasi-2D mixed-halide perovskite films as the emissive layer; TPBi as the electron transporting layer; $\mathrm{LiF} / \mathrm{Al}$ as the cathode (Figure 1a). The incorporation of bulky organic cations such as PMA into the perovskite structure results in a layered perovskite structure with chemical formula $\mathrm{PMA}_{2} \mathrm{~A}_{n-1} \mathrm{~Pb}_{n} \mathrm{X}_{3 \mathrm{n}+1}(n=2,3,4,5 \ldots$, where $n$ is the number of perovskite layers) [27], which is shown schematically in Figure 1b. To investigate the effect of cations on the properties of mixed-halide quasi-2D perovskite, we fabricated perovskite films with three different A-site cations (FA, MA, Cs) (Figure 1c), which are the most widely used cations for metal halide perovskite structures.

XRD patterns were obtained to investigate the crystal structures of mixed-halide quasi-2D perovskite (Figure 2a). XRD patterns show peaks below $10^{\circ}$ that correspond to the small $n$ quasi-2D perovskite structures [28-30] $\left(\mathrm{FA}=5.20^{\circ}, \mathrm{MA}=5.20^{\circ}, \mathrm{Cs}=5.26^{\circ}\right)$ and peaks corresponding to the 3D-like perovskite layer in the quasi-2D perovskite structure $\left(\mathrm{FA}=15.36^{\circ}, \mathrm{MA}=14.94^{\circ}, \mathrm{Cs}=14.82^{\circ}\right)$. Compared to the other cations-based perovskite, Cs-based quasi-2D perovskite films show a more dominant peak below $10^{\circ}$, corresponding with the small $n$ quasi-2D perovskite structures. These results indicate that either more quasi-2D perovskite structures were formed, or that Cs-based quasi-2D perovskite structures have higher crystallinity. SEM images were obtained to observe the morphology 
of quasi-2D perovskite (Figure S1). All the perovskite films with different cations show uniform and pinhole-free surface morphologies.

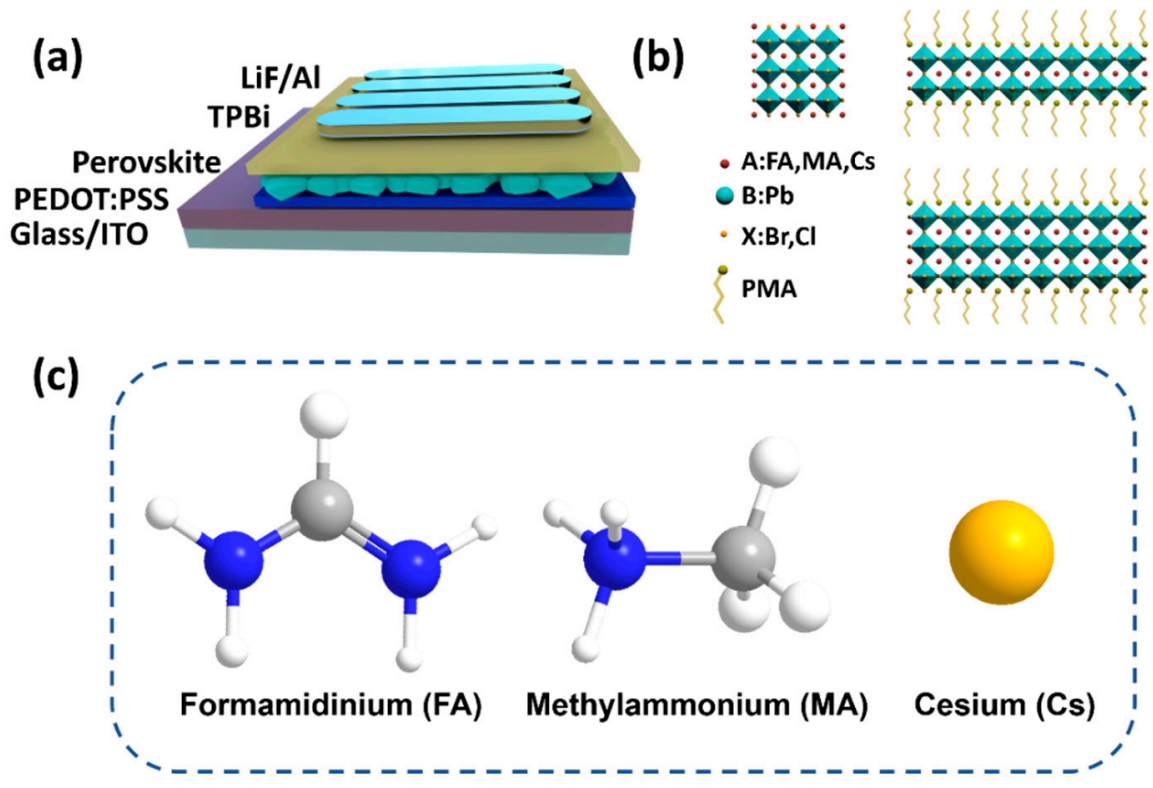

Figure 1. (a) Schematic illustration of quasi-2D perovskite light-emitting diodes (PeLEDs) architecture. (b) Schematic illustration of quasi-2D $\mathrm{PMA}_{2} \mathrm{~A}_{2} \mathrm{~Pb}_{3} \mathrm{Br}_{8} \mathrm{Cl}_{2}$ (A = FA, MA, Cs) perovskite structure. (c) Schematic illustration of different cation structures.

(a)

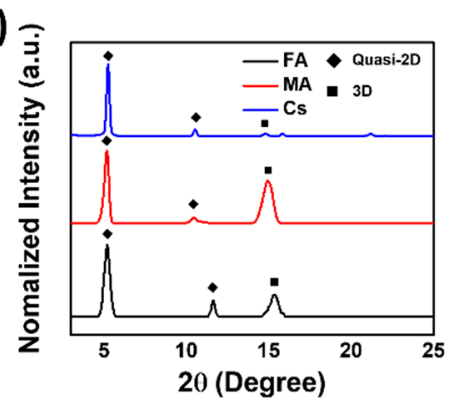

(b)

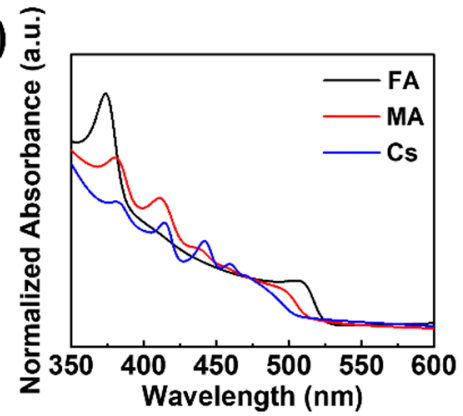

(c)

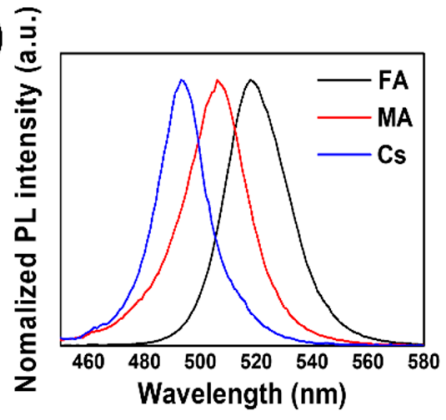

Figure 2. (a) X-ray diffraction (XRD) patterns of FA, MA, and Cs-based quasi-2D perovskite films. (b) Absorption, and (c) photoluminescence (PL) spectra of FA, MA, and Cs-based quasi-2D perovskite films.

To study the optical properties of quasi-2D perovskite films with different A-site cations, PL and absorption spectra were obtained for each sample (Figure $2 b, c)$. The absorption spectra of quasi-2D perovskite films shows multiple higher energy absorption peaks, which clearly indicates the formation of multi-dimensional domains in the films $(n=1,2,3, \ldots)$. Although FA-based quasi-2d perovskite films show one dominant peak at wavelength of $375 \mathrm{~nm}$, Cs and MA-based quasi-2D perovskite films show multiple peaks. These results indicate the formation of more dispersive multi-dimensional domains in the Cs and MA-based quasi-2D perovskite films compared to the FA-based quasi-2D perovskite films. Although same molar ratio of halide $(\mathrm{Br}: \mathrm{Cl}=8: 2)$ and bulky cations were introduced, quasi-2D perovskite films show a different maximum PL wavelength (FA: $518 \mathrm{~nm}$ MA: $506 \mathrm{~nm}$ Cs: $493 \mathrm{~nm}$ ). This trend is well matched with the absorption onset of quasi-2D perovskite films shown in Figure 2b. The differences in emission wavelengths arises from the differences in ion sizes between the MA, FA, and Cs cations [31], with the smaller cations forming the larger-bandgap perovskites for more blue-shifted emission. 
The characteristics of PeLEDs fabricated using quasi-2D mixed-halide $\mathrm{PMA}_{2} \mathrm{~A}_{2} \mathrm{~Pb}_{3} \mathrm{Br}_{8} \mathrm{Cl}_{2}$ (A = FA, MA, Cs) films as an emitting layer are shown in Figure 3 and Table 1 . The J-V and L-V data of PeLEDs are shown in Figure 3a,b. FA, MA, and Cs-based PeLEDs each showed a maximum luminance of 1560 at $6.4 \mathrm{~V}, 280$ at $8.2 \mathrm{~V}$, and $790 \mathrm{~cd} / \mathrm{m}^{2}$, respectively, at $10.8 \mathrm{~V}$. The EQE and luminance efficiency of PeLEDs are shown in Figure 3c,d. The FA-based PeLED showed a maximum EQE of $1.41 \%$ and luminance efficiency of $4.10 \mathrm{~cd} / \mathrm{A}$ at $5.0 \mathrm{~V}$, whereas the MA-based PeLEDs showed a maximum EQE of $0.88 \%$ at $5.6 \mathrm{~V}$ and luminance efficiency of $1.80 \mathrm{~cd} / \mathrm{A}$ at $6.0 \mathrm{~V}$. Finally, the Cs-based PeLED showed a maximum EQE of $0.42 \%$ at $9.8 \mathrm{~V}$ and luminance efficiency of $0.76 \mathrm{~cd} / \mathrm{A}$ at $10.0 \mathrm{~V}$.

(a)

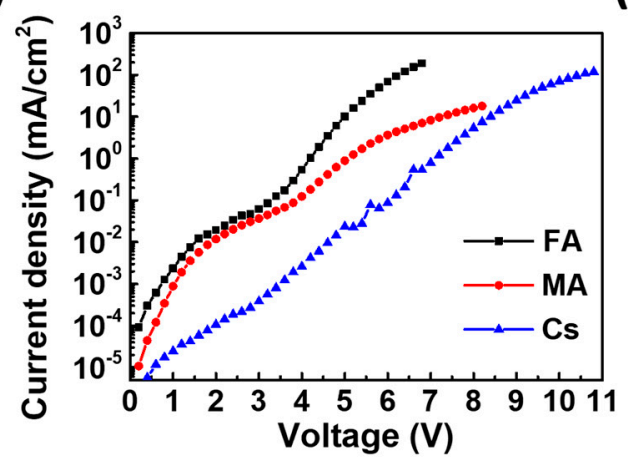

(c)

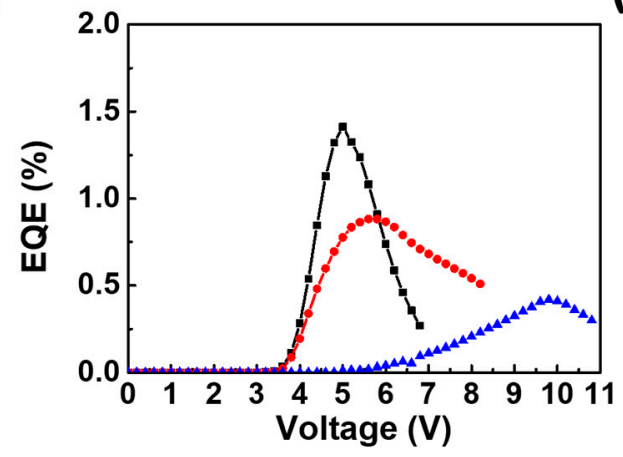

(b)

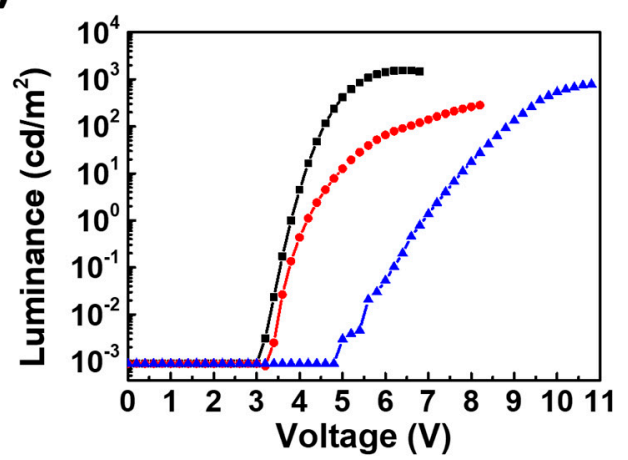

(d)

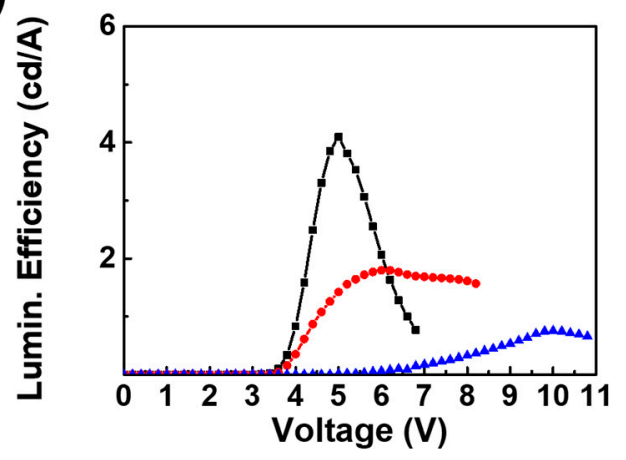

Figure 3. (a) Current density-voltage curves, (b) luminance-voltage curves, (c) EQE-voltage curves and (d) luminance efficiency-voltage curves of FA, MA, and Cs-based quasi-2D PeLEDs.

Table 1. Device performance of FA, MA, and Cs-based quasi-2D PeLEDs.

\begin{tabular}{|c|c|c|c|c|c|}
\hline $\begin{array}{c}\text { Device } \\
\text { Configuration }\end{array}$ & $\begin{array}{c}\mathrm{L}_{\max }\left[\mathrm{cd} / \mathrm{m}^{2}\right] \\
@ \operatorname{Bias}(\mathrm{V})\end{array}$ & $\begin{array}{c}\mathrm{LE} \text { max }[\mathrm{cd} / \mathrm{A}] \\
@ \text { Bias (V) }\end{array}$ & $\begin{array}{c}\mathrm{EQE} \max [\%] \\
@ \text { Bias (V) }\end{array}$ & $\begin{array}{c}\text { Turn-on } \\
\text { Voltage }[\mathrm{V}] \\
{\left[0.1 \mathrm{~cd} / \mathrm{m}^{2}\right]}\end{array}$ & $\begin{array}{c}\text { Peak } \\
\text { Wavelength } \\
{[\mathrm{nm}]}\end{array}$ \\
\hline FA & $1560(6.4 \mathrm{~V})$ & $4.10(5.0 \mathrm{~V})$ & $1.41(5.0 \mathrm{~V})$ & $3.6 \mathrm{~V}$ & 509 \\
\hline MA & $280(8.2 \mathrm{~V})$ & $1.80(6.0 \mathrm{~V})$ & $0.88(5.6 \mathrm{~V})$ & $3.8 \mathrm{~V}$ & 494 \\
\hline Cs & $790(10.8 \mathrm{~V})$ & $0.76(10.0 \mathrm{~V})$ & $0.42(9.8 \mathrm{~V})$ & $6.2 \mathrm{~V}$ & 488 \\
\hline
\end{tabular}

Halide segregation-induced EL peak instability has been widely reported in mixed-halide PeLEDs. To investigate the cation-dependent EL stability, EL spectra with different current densities were measured with different cation (MA, FA, Cs) based quasi-2D PeLEDs (Figure 4a-d). The applied current density was increased from 0.1 to $20 \mathrm{~mA} / \mathrm{cm}^{2}$. Although substantial amounts of chloride $(\mathrm{Br}: \mathrm{Cl}=8: 2)$ were introduced, we observed stable EL spectra stability with negligible peak shifts and FWHM. However, MA-based quasi-2D PeLEDs shows clear EL spectra instability with $18 \mathrm{~nm}$ of EL peak shifts and $4 \mathrm{~nm}$ of FWHM broadening induced by halide segregation. The photographs and videos of FA, MA, and Cs-based quasi-2D PeLEDs lighting at constant current density of $5.2 \mathrm{~mA} / \mathrm{cm}^{2}$ are shown in Figure S2 and Video S1. As the MA cations (2.29 Debye) have much higher dipole moment compared 
to the FA (0.21 Debye), and Cs (0 Debye) cations [25], we postulate that instability in the EL spectrum and halide segregation of MA-based PeLEDs originate from the polaronic effect due to the large dipole moment of MA.
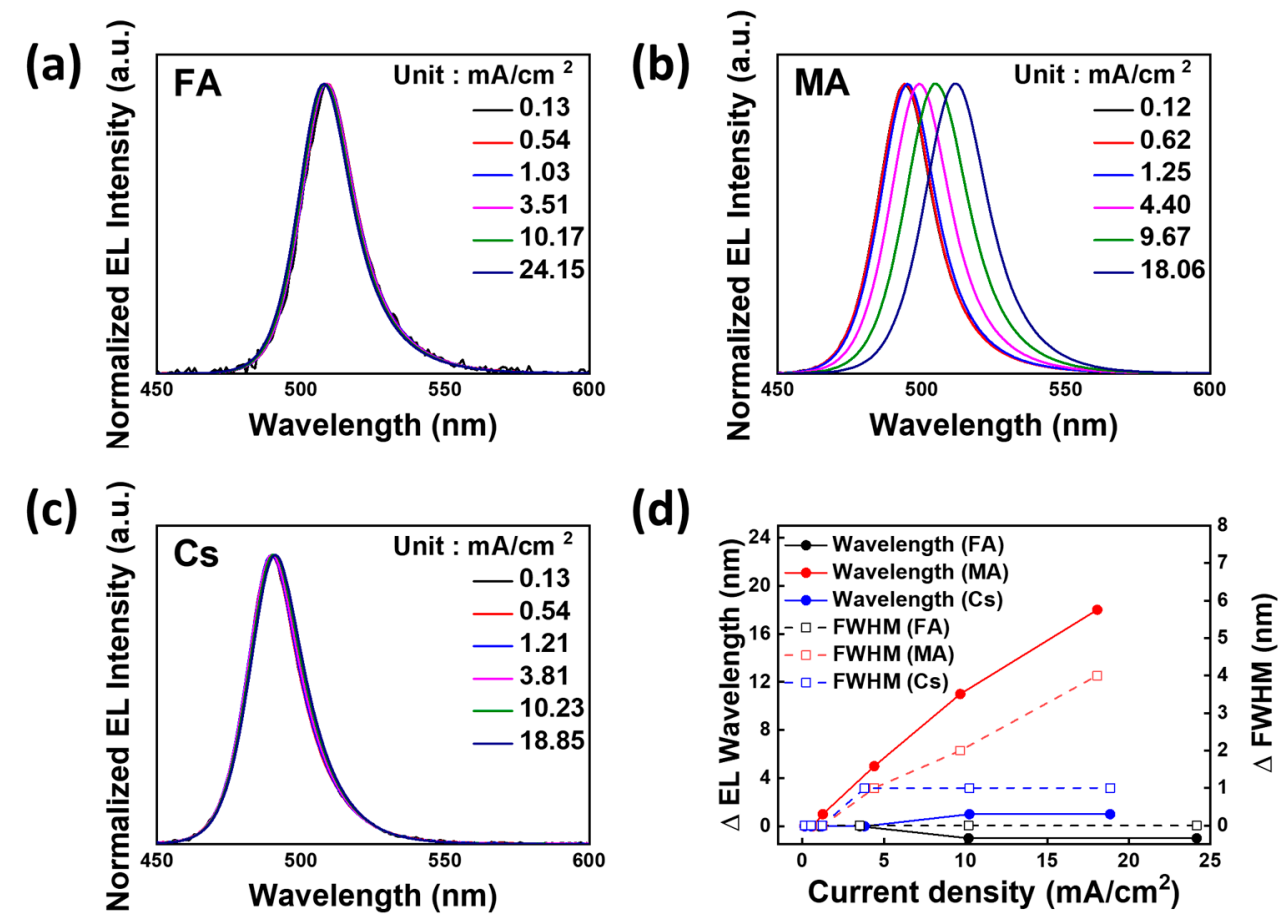

Figure 4. Electroluminescence (EL) spectrum of (a) FA-based, (b) MA-based, (c) and Cs-based quasi-2D PeLEDs at various applied voltages. (d) Changes in the EL wavelength and full width at half-maximum (FWHM) of FA, MA, and Cs-based quasi-2D PeLEDs.

\section{Conclusions}

We studied the effect of A-site cations on the color tunability and EL spectrum stability of mixed-halide quasi-2D PeLEDs containing $\mathrm{Br}$ and $\mathrm{Cl}$. The formation of a quasi-2D perovskite structure was confirmed with a bulky PMACl ligand using XRD and absorption spectrum measurements. Our PeLEDs with FA, MA, and Cs A-site cations showed luminances of 1560, 280 and $790 \mathrm{~cd} / \mathrm{m}^{2}$, EQEs of $1.41,0.88$ and $0.42 \%$ and wavelengths of $509,494,488 \mathrm{~nm}$, respectively. Our results show that the stability of the EL spectrum is highly dependent on the nature of A-site cations. Although FA and Cs-based PeLEDs show negligible EL spectrum changes under high current density at more than $15 \mathrm{~mA} / \mathrm{cm}^{2}$, MA-based PeLEDs show severe EL spectrum changes at the same current density. Therefore, we postulate that instability in the EL spectrum of MA-based PeLEDs originates from the large dipole moment of MA cations; our work suggests that a judicious choice of A-site cation is crucial to achieve efficient and stable blue-emissive PeLEDs.

Supplementary Materials: The following are available online at http://www.mdpi.com/1996-1073/13/24/6689/s1, Figure S1: Top-view SEM images of quasi-2D perovskite films, Figure S2: Photo of FA, MA, and Cs-based PeLEDs lighting at constant current density. Video S1: Video of FA, MA, and Cs-based PeLEDs lighting at constant current density.

Author Contributions: Conceptualization, C.H.J. and S.L.; device fabrication, C.H.J. and S.L.; validation, J.H.P. and C.H.J.; formal analysis, J.H.P., S.L. and B.R.L.; investigation, J.H.P., C.H.J. and E.D.J.; data curation, S.L., B.R.L. and M.H.S.; writing-original draft preparation, J.H.P., C.H.J. and B.R.L.; writing-review and editing, S.L., B.R.L. and M.H.S.; supervision, B.R.L. and M.H.S.; project administration, B.R.L. and M.H.S.; funding acquisition, B.R.L. and M.H.S.; J.H.P. and C.H.J. contributed equally to this work. All authors have read and agreed to the published version of the manuscript. 
Funding: This research received no external funding.

Acknowledgments: This work was supported by the National Research Foundation (NRF) of Korea (NRF-2018R1C1B6005778, NRF-2020R1A4A1018163, NRF-2018R1A2B2006198) and the Materials Innovation Project (NRF-2020M3H4A3081793) funded by the National Research Foundation of Korea. This work was supported by the Korea Institute of Energy Technology Evaluation and Planning (KETEP) and the Ministry of Trade, Industry and Energy (MOTIE) of Korea (No, 20163010012450).

Conflicts of Interest: The authors declare no conflict of interest.

\section{References}

1. Tan, Z.-K.; Moghaddam, R.S.; Lai, M.L.; Docampo, P.; Higler, R.; Deschler, F.; Price, M.; Sadhanala, A.; Pazos, L.M.; Credgington, D.; et al. Bright light-emitting diodes based on organometal halide perovskite. Nat. Nanotechnol. 2014, 9, 687-692. [CrossRef]

2. Cho, H.; Jeong, S.-H.; Park, M.-H.; Kim, Y.-H.; Wolf, C.; Lee, C.-L.; Heo, J.H.; Sadhanala, A.; Myoung, N.; Yoo, S.; et al. Overcoming the electroluminescence efficiency limitations of perovskite light-emitting diodes. Science 2015, 350, 1222. [CrossRef] [PubMed]

3. Lee, S.; Park, J.H.; Lee, B.R.; Jung, E.D.; Yu, J.C.; Di Nuzzo, D.; Friend, R.H.; Song, M.H. Amine-Based Passivating Materials for Enhanced Optical Properties and Performance of Organic-Inorganic Perovskites in Light-Emitting Diodes. J. Phys. Chem. Lett. 2017, 8, 1784-1792. [CrossRef]

4. Xiao, Z.; Kerner, R.A.; Zhao, L.; Tran, N.L.; Lee, K.M.; Koh, T.-W.; Scholes, G.D.; Rand, B.P. Efficient perovskite light-emitting diodes featuring nanometre-sized crystallites. Nat. Photonics 2017, 11, 108-115. [CrossRef]

5. Yuan, M.; Quan, L.N.; Comin, R.; Walters, G.; Sabatini, R.; Voznyy, O.; Hoogland, S.; Zhao, Y.; Beauregard, E.M.; Kanjanaboos, P.; et al. Perovskite energy funnels for efficient light-emitting diodes. Nat. Nanotechnol. 2016, 11, 872-877. [CrossRef]

6. Yang, X.; Zhang, X.; Deng, J.; Chu, Z.; Jiang, Q.; Meng, J.; Wang, P.; Zhang, L.; Yin, Z.; You, J. Efficient green light-emitting diodes based on quasi-two-dimensional composition and phase engineered perovskite with surface passivation. Nat. Commun. 2018, 9, 570. [CrossRef]

7. Zou, W.; Li, R.; Zhang, S.; Liu, Y.; Wang, N.; Cao, Y.; Miao, Y.; Xu, M.; Guo, Q.; Di, D.; et al. Minimising efficiency roll-off in high-brightness perovskite light-emitting diodes. Nat. Commun. 2018, 9, 608. [CrossRef]

8. Hassan, Y.; Ashton, O.J.; Park, J.H.; Li, G.; Sakai, N.; Wenger, B.; Haghighirad, A.-A.; Noel, N.K.; Song, M.H.; Lee, B.R.; et al. Facile Synthesis of Stable and Highly Luminescent Methylammonium Lead Halide Nanocrystals for Efficient Light Emitting Devices. J. Am. Chem. Soc. 2019, 141, 1269-1279. [CrossRef]

9. Chiba, T.; Hayashi, Y.; Ebe, H.; Hoshi, K.; Sato, J.; Sato, S.; Pu, Y.-J.; Ohisa, S.; Kido, J. Anion-exchange red perovskite quantum dots with ammonium iodine salts for highly efficient light-emitting devices. Nat. Photonics 2018, 12, 681-687. [CrossRef]

10. Cao, Y.; Wang, N.; Tian, H.; Guo, J.; Wei, Y.; Chen, H.; Miao, Y.; Zou, W.; Pan, K.; He, Y.; et al. Perovskite light-emitting diodes based on spontaneously formed submicrometre-scale structures. Nature 2018, 562, 249-253. [CrossRef]

11. Dong, Y.; Wang, Y.-K.; Yuan, F.; Johnston, A.; Liu, Y.; Ma, D.; Choi, M.-J.; Chen, B.; Chekini, M.; Baek, S.-W.; et al. Bipolar-shell resurfacing for blue LEDs based on strongly confined perovskite quantum dots. Nat. Nanotechnol. 2020, 15, 668-674. [CrossRef] [PubMed]

12. Wang, Q.; Wang, X.; Yang, Z.; Zhou, N.; Deng, Y.; Zhao, J.; Xiao, X.; Rudd, P.; Moran, A.; Yan, Y.; et al. Efficient sky-blue perovskite light-emitting diodes via photoluminescence enhancement. Nat. Commun. 2019, 10, 5633. [CrossRef] [PubMed]

13. Liu, Y.; Yu, Z.; Chen, S.; Park, J.H.; Jung, E.D.; Lee, S.; Kang, K.; Ko, S.-J.; Lim, J.; Song, M.H.; et al. Boosting the efficiency of quasi-2D perovskites light-emitting diodes by using encapsulation growth method. Nano Energy 2021, 80, 105511. [CrossRef]

14. Righetto, M.; Meggiolaro, D.; Rizzo, A.; Sorrentino, R.; He, Z.; Meneghesso, G.; Sum, T.C.; Gatti, T.; Lamberti, F. Coupling halide perovskites with different materials: From doping to nanocomposites, beyond photovoltaics. Prog. Mater. Sci. 2020, 110, 100639. [CrossRef]

15. Noh, J.H.; Im, S.H.; Heo, J.H.; Mandal, T.N.; Seok, S.I. Chemical Management for Colorful, Efficient, and Stable Inorganic-Organic Hybrid Nanostructured Solar Cells. Nano Lett. 2013, 13, 1764-1769. [CrossRef] 
16. Protesescu, L.; Yakunin, S.; Bodnarchuk, M.I.; Krieg, F.; Caputo, R.; Hendon, C.H.; Yang, R.X.; Walsh, A.; Kovalenko, M.V. Nanocrystals of Cesium Lead Halide Perovskites (CsPbX3, X = Cl, Br, and I): Novel Optoelectronic Materials Showing Bright Emission with Wide Color Gamut. Nano Lett. 2015, 15, 3692-3696. [CrossRef]

17. Draguta, S.; Sharia, O.; Yoon, S.J.; Brennan, M.C.; Morozov, Y.V.; Manser, J.S.; Kamat, P.V.; Schneider, W.F.; Kuno, M. Rationalizing the light-induced phase separation of mixed halide organic-inorganic perovskites. Nat. Commun. 2017, 8, 200. [CrossRef]

18. Li, G.; Rivarola, F.W.R.; Davis, N.J.L.K.; Bai, S.; Jellicoe, T.C.; de la Peña, F.; Hou, S.; Ducati, C.; Gao, F.; Friend, R.H.; et al. Highly Efficient Perovskite Nanocrystal Light-Emitting Diodes Enabled by a Universal Crosslinking Method. Adv. Mater. 2016, 28, 3528-3534. [CrossRef]

19. Bischak, C.G.; Hetherington, C.L.; Wu, H.; Aloni, S.; Ogletree, D.F.; Limmer, D.T.; Ginsberg, N.S. Origin of Reversible Photoinduced Phase Separation in Hybrid Perovskites. Nano Lett. 2017, 17, 1028-1033. [CrossRef]

20. Bischak, C.G.; Wong, A.B.; Lin, E.; Limmer, D.T.; Yang, P.; Ginsberg, N.S. Tunable Polaron Distortions Control the Extent of Halide Demixing in Lead Halide Perovskites. J. Phys. Chem. Lett. 2018, 9, 3998-4005. [CrossRef]

21. Wang, X.; Meng, Q. Optimal price decisions for joint ventures between port operators and shipping lines under the congestion effect. Eur. J. Oper. Res. 2019, 273, 695-707. [CrossRef]

22. Belisle, R.A.; Bush, K.A.; Bertoluzzi, L.; Gold-Parker, A.; Toney, M.F.; McGehee, M.D. Impact of Surfaces on Photoinduced Halide Segregation in Mixed-Halide Perovskites. ACS Energy Lett. 2018, 3, 2694-2700. [CrossRef]

23. Hoke, E.T.; Slotcavage, D.J.; Dohner, E.R.; Bowring, A.R.; Karunadasa, H.I.; McGehee, M.D. Reversible photo-induced trap formation in mixed-halide hybrid perovskites for photovoltaics. Chem. Sci. 2015, 6, 613-617. [CrossRef]

24. Saliba, M.; Matsui, T.; Seo, J.-Y.; Domanski, K.; Correa-Baena, J.-P.; Nazeeruddin, M.K.; Zakeeruddin, S.M.; Tress, W.; Abate, A.; Hagfeldt, A.; et al. Cesium-containing triple cation perovskite solar cells: Improved stability, reproducibility and high efficiency. Energy Environ. Sci. 2016, 9, 1989-1997. [CrossRef]

25. Frost, J.M.; Butler, K.T.; Brivio, F.; Hendon, C.H.; van Schilfgaarde, M.; Walsh, A. Atomistic Origins of High-Performance in Hybrid Halide Perovskite Solar Cells. Nano Lett. 2014, 14, 2584-2590. [CrossRef] [PubMed]

26. Lee, S.; Jang, C.H.; Nguyen, T.L.; Kim, S.H.; Lee, K.M.; Chang, K.; Choi, S.S.; Kwak, S.K.; Woo, H.Y.; Song, M.H. Conjugated Polyelectrolytes as Multifunctional Passivating and Hole-Transporting Layers for Efficient Perovskite Light-Emitting Diodes. Adv. Mater. 2019, 31, 1900067. [CrossRef] [PubMed]

27. Kieslich, G.; Sun, S.; Cheetham, A.K. An extended Tolerance Factor approach for organic-inorganic perovskites. Chem. Sci. 2015, 6, 3430-3433. [CrossRef] [PubMed]

28. Cao, D.H.; Stoumpos, C.C.; Farha, O.K.; Hupp, J.T.; Kanatzidis, M.G. 2D Homologous Perovskites as Light-Absorbing Materials for Solar Cell Applications. J. Am. Chem. Soc. 2015, 137, 7843-7850. [CrossRef]

29. Quan, L.N.; Yuan, M.; Comin, R.; Voznyy, O.; Beauregard, E.M.; Hoogland, S.; Buin, A.; Kirmani, A.R.; Zhao, K.; Amassian, A.; et al. Ligand-Stabilized Reduced-Dimensionality Perovskites. J. Am. Chem. Soc. 2016, 138, 2649-2655. [CrossRef]

30. Jang, C.H.; Harit, A.K.; Lee, S.; Kim, S.H.; Jeong, J.-E.; Park, J.H.; Jung, E.D.; Ha, J.M.; Kwak, S.K.; Woo, H.Y.; et al. Sky-Blue-Emissive Perovskite Light-Emitting Diodes: Crystal Growth and Interfacial Control Using Conjugated Polyelectrolytes as a Hole-Transporting Layer. ACS Nano 2020, 14, 13246-13255. [CrossRef]

31. Eperon, G.E.; Stranks, S.D.; Menelaou, C.; Johnston, M.B.; Herz, L.M.; Snaith, H.J. Formamidinium lead trihalide: A broadly tunable perovskite for efficient planar heterojunction solar cells. Energy Environ. Sci. 2014, 7, 982-988. [CrossRef]

Publisher's Note: MDPI stays neutral with regard to jurisdictional claims in published maps and institutional affiliations.

(C) 2020 by the authors. Licensee MDPI, Basel, Switzerland. This article is an open access article distributed under the terms and conditions of the Creative Commons Attribution (CC BY) license (http://creativecommons.org/licenses/by/4.0/). 